\title{
A role for the Rcs phosphorelay in regulating expression of plant cell wall degrading enzymes in Pectobacterium carotovorum subsp. carotovorum
}

Correspondence

Andres Mäe

amae@ebc.ee

Received 20 August 2009

Revised 20 January 2010

Accepted 26 January 2010

\author{
Liis Andresen, Erki Sala, Viia Kõiv and Andres Mäe
}

Department of Genetics, Institute of Molecular and Cell Biology, University of Tartu, Estonian Biocenter, 23 Riia Street, Tartu 51010, Estonia

\section{INTRODUCTION}

The phytopathogenicity of Pectobacterium carotovorum subsp. carotovorum $(P c c)$ is largely due its capacity to synthesize and secrete plant cell wall degrading enzymes (PCWDE), including pectinases, cellulases and protease (Heikinheimo et al., 1995; Marits et al., 1999; Mäe et al., 1995; Pirhonen et al., 1991). Survival of infecting Pcc largely depends on production of PCWDE for the transition from latent infection to disease state. A number of global and specific regulatory genes contribute to expression of PCWDE in Pcc (Burr et al., 2006; Chatterjee et al., 1995; Cui et al., 1995, 1999, 2001, 2005; Eriksson et al., 1998; Flego et al., 2000; Harris et al., 1998; Hyytiäinen et al., 2003; Liu

Abbreviations: Pba, Pectobacterium atrosepticum SCRI 1043; PcC, Pectobacterium carotovorum subsp. carotovorum; PCWDE, plant cell wall degrading enzymes; PGA, polygalacturonic acid.

The GenBank/EMBL/DDBJ accession numbers for the $r p r A$, flhDC and rsmB genes are G0339472, GO344498, and GO344499, respectively.

A supplementary table listing predicted RcsB-binding sites in Pectobacterium atrosepticum is available with the online version of this paper. et al., 1998, 1999; Sjöblom et al., 2006). The posttranscriptional Rsm system plays a key role in regulating the expression of PCWDE (Chatterjee et al., 1995; Cui et al., 1995; Liu et al., 1998).The Rsm system consists of two regulators in Pcc: a small protein, RsmA, and RsmB RNA. RsmA is a post-transcriptional global regulator that is thought to bind mRNAs of PCWDE genes and affect their stability, whereas RsmB RNA binds multiple molecules of RsmA, thereby neutralizing its effect (Liu et al., 1998). Recently, the Rsm system was shown to be dependent on expression of a global regulator of flagellar genes, FlhDC. FlhDC activates the expression of PCWDE in Pcc strain 71 by modulating transcription of RsmB (Cui et al., 2008).

Motility is a key feature of many microbes' physiology, and flagella provide the necessary propulsion to the microbes in a liquid environment. FlhDC, which regulates the expression of flagellar genes (for a review, see Prüß, 2000), also regulates the consumption of glucose (Entner-Doudoroff pathway) and anaerobic respiration in Escherichia coli, as well as induction of purine and pyrimidine synthesis and repression of the urea cycle in Yersinia enterocolitica (Kapatral et al., 2004; Prüß et al., 2001, 2003). Flagellar 
motility is also a pathogenicity determinant in pectobacteria, and appears to be necessary for the successful invasion and infection of a plant host (Pirhonen et al., 1991; Pérombelon, 2002). Mutants defective in either flagellar synthesis or rotation exhibited a reduced ability to elicit soft-rot symptoms, despite the normal expression of PCWDE (Hossain et al., 2005).

Previously, we demonstrated that both PCWDE synthesis and motility are regulated by the Rcs phosphorelay in $P c c$ (Andresen et al., 2007). The Rcs phosphorelay has been implicated in the synthesis of virulence factors in $P c c$ and other plant-pathogenic bacteria and also in human pathogens (Hinchliffe et al., 2008; Mouslim et al., 2004; Wang et al., 2009, 2007). RcsB activates the biosynthesis of capsular exopolysaccharides, transcription of the cell division gene, $f t s Z$, transcription of a cell envelope protein, $o s m C$, and transcription of RprA RNA to increase expression of the stationary-phase sigma factor, RpoS, in E. coli (Carballes et al., 1999; Davalos-Garcia et al., 2001; Gervais et al., 1992; Gottesman et al., 1985; Majdalani et al., 2002). Francez-Charlot et al. (2003) demonstrated that the Rcs phosphorelay system represses motility through the direct binding of RcsB to the promoter of $f l h D C$ in E. coli.

To gain further insight into the regulatory network that controls virulence gene expression in $P c c$, we focused on the contributions of the Rcs phosphorelay to the expression of PCWDE. We purified RcsB from $P c c$ and investigated its mode of action in regulating the virulence phenotype: whether it directly binds to the promoters of PCWDE to repress the expression, indirectly represses transcription of virulence activator genes, or activates transcription of virulence repressor genes.

\section{METHODS}

Bacterial strains, vectors, and growth conditions. Strains and plasmids used in this study are listed in Table 1. Pectobacterium carotovorum subsp. carotovorum $(P c c)$ strains were grown at $30{ }^{\circ} \mathrm{C}$, and Escherichia coli was grown at $37^{\circ} \mathrm{C}$. Bacteria were grown on $\mathrm{LB}$ medium or M9 minimal salts medium containing $0.4 \%$ glycerol (Miller, 1972; Sambrook \& Russell, 2001). When required, media were supplemented with $0.2 \%(\mathrm{w} / \mathrm{v})$ polygalacturonic acid (PGA; Sigma), $150 \mu \mathrm{g}$ ampicillin (Amp) $\mathrm{ml}^{-1}, 100 \mu \mathrm{g}$ kanamycin $(\mathrm{Km})$ $\mathrm{ml}^{-1}$ or $25 \mu \mathrm{g}$ chloramphenicol $(\mathrm{Cm}) \mathrm{ml}^{-1}$.

Predicted RcsB-binding sites in Pectobacterium. Prediction of the RcsB regulon in Pectobacterium was performed using a web-based prediction program, Virtual Footprint Version 3.0 (Münch et al., 2005) on the genome sequence of Pectobacterium atrosepticum strain SCRI 1043 (Pba) (http://www.sanger.ac.uk/Projects/E_carotovora/; Bell et al., 2004). A position-specific weight matrix was generated using RcsB-binding sites described by Wehland \& Bernhard (2000), as well as RcsB-binding sequences identified in the promoters of $f l h D C$, rprA, osm C and fts $Z$ genes in E. coli (Carballes et al., 1999; DavalosGarcia et al., 2001; Francez-Charlot et al., 2003; Majdalani et al., 2002). The sensitivity threshold was set to $0.8-11.3$, only RcsB-binding sites within $350 \mathrm{bp}$ of the start of translation were considered, and the search was restricted to intergenic regions.
PCR cloning and DNA sequencing. Standard DNA techniques described in Sambrook \& Russell (2001) were used. Oligonucleotide primers used in this study for PCR amplification are listed in Table 2. The genomic regions of the $r p r A$, flhDC and $r s m B$ genes of $P c c$ strain SCC3193 were cloned by using primers obtained from the genome sequence of $\mathrm{Pba}$. The amplified fragments were cloned into plasmid pTZ57R/T, and sequenced. The GenBank accession numbers for the rprA, flhDC and $r s m B$ genes are GQ339472, GQ344498, and GQ344499, respectively.

Overexpression and purification of histidine-tagged RcsB and RcsBD56E. The $r c s B$ gene was amplified using primers RcsBNcoI and RcsBHindIII and was cloned into the SmaI site of Bluescript SK + to yield pLA1. The $r c s B$ gene was subsequently subcloned using $\mathrm{NcoI}$ and HindIII into plasmid pET24d having a C-terminal His ${ }_{6}$ tag (pET24d$r c s B)$. RcsB was overexpressed from this plasmid as a fusion protein with a C-terminal $\mathrm{His}_{6}$ tag and purified as described by Hõrak et al. (2004). The protocol was modified to include buffers A/B [100 mM Tris/HCl (pH 7.5), $1 \mathrm{M} \mathrm{NaCl}, 25 \mathrm{mM}$ imidazole, $10 \mathrm{mM}$ DTT, $0.1 \mathrm{mM}$ EDTA, $0.1 \%$ Triton X-100, $5 \%$ glycerol] and C [100 mM Tris/HCl (pH 7.5), $500 \mathrm{mM} \mathrm{NaCl}, 500 \mathrm{mM}$ imidazole, $10 \mathrm{mM}$ DTT, $0.1 \mathrm{mM}$ EDTA, $0.1 \%$ Triton X-100, and $50 \%$ glycerol]. Purified protein was dialysed against storage buffer $[10 \mathrm{mM}$ Tris/ $\mathrm{HCl}(\mathrm{pH} 7.5), 200 \mathrm{mM} \mathrm{KCl}, 1 \mathrm{mM}$ DTT, $0.5 \mathrm{mM}$ EDTA, $50 \%$ glycerol] and stored at $-20{ }^{\circ} \mathrm{C}$.

Site-directed mutagenesis and purification of modified protein. The sequence of the $r c s B$ in which the conserved aspartate codon (D56) was substituted with a codon for glutamic acid was generated as follows. Partial sequence of $r c s B$ was amplified with primers rcsBalg and RcsBD56E from Pcc chromosomal DNA, purified with the UltraClean 15 DNA Purification kit (MO BIO), and subsequently used as a primer in a PCR paired with primer rcsCend, and chromosome of $P c c$ as a template. Amplified PCR product was cloned into the cloning vector pJET1 to yield pJET1-rcsBD56E, according to the supplied protocol (Fermentas). The $r c s B D 56 E$ gene was amplified using primers RcsBNcoI and RcsBHindIII with plasmid pJET1-rcsBD56E as a template. The subsequent cloning, protein expression and purification procedures were the same as for histidine-tagged RcsB.

DNase I footprinting. DNA fragments for DNase I footprinting assays were amplified by PCR from genomic DNA of Pcc SCC3193 and one of the primers end-labelled with $\left[\gamma^{32} \mathrm{P}\right] \mathrm{ATP}$ by polynucleotide kinase (Fermentas). Amplified DNA fragments included: (i) flhDC (203 bp) having upstream sequences -374 bp to $-171 \mathrm{bp}$ using primers flhD1 and flhD2; (ii) $\operatorname{rprA}(159 \mathrm{bp}$ ) including upstream sequences $-124 \mathrm{bp}$ to $+35 \mathrm{bp}$ using primers rprAFP1 and rprAFP2; (iii) $r s m B(325 \mathrm{bp})$ including upstream sequences $-287 \mathrm{bp}$ to $+38 \mathrm{bp}$ using primers rsmBpA and rsmBpY; and (iv) prtW (269 bp) including upstream sequences $-55 \mathrm{bp}$ to $+214 \mathrm{bp}$ using primers PROS and PRIMEX2. DNase I footprinting reactions were performed as described by Ilves et al. (2004), except that 0.01U DNase I (Fermentas) was used and the concentration of RcsB-6His or RcsBD56E-6His ranged from 0.5 to $20 \mu \mathrm{M}$. DNA sequencing reactions were performed using a Sequenase Version 2.0 kit (US Biochemicals). Footprinting and sequencing reactions were resolved and dried in $6.5 \%$ denaturing polyacrylamide gels and scanned using a Typhoon phosphoimager screen (Amersham Biosciences).

Construction of mutant strains. The $r c s B:: K m$ fragment was amplified using primers rcsBP1 and rcsBP2, with plasmid, pKD4 as template. Replacement of chromosomal $r c s B$ with $r c s B:: K m$ was performed using the $\lambda$ Red system (Datsenko \& Wanner, 2000) to yield mutant SCC6030. The flhDC-negative mutant (SCC6028) was generated as described by Datsenko \& Wanner (2000) using primers flhDP1 and flhDP2, which amplified the cat $\left(\mathrm{Cm}^{\mathrm{R}}\right)$ gene from pKD3 with $49 \mathrm{bp}$ of the $f l h D$ sequence on either side to position the insert +1 with respect to the start codon of $f l h D$. The $f l h D / r c s B$ double mutant 
Table 1. Strains and plasmids used in this study

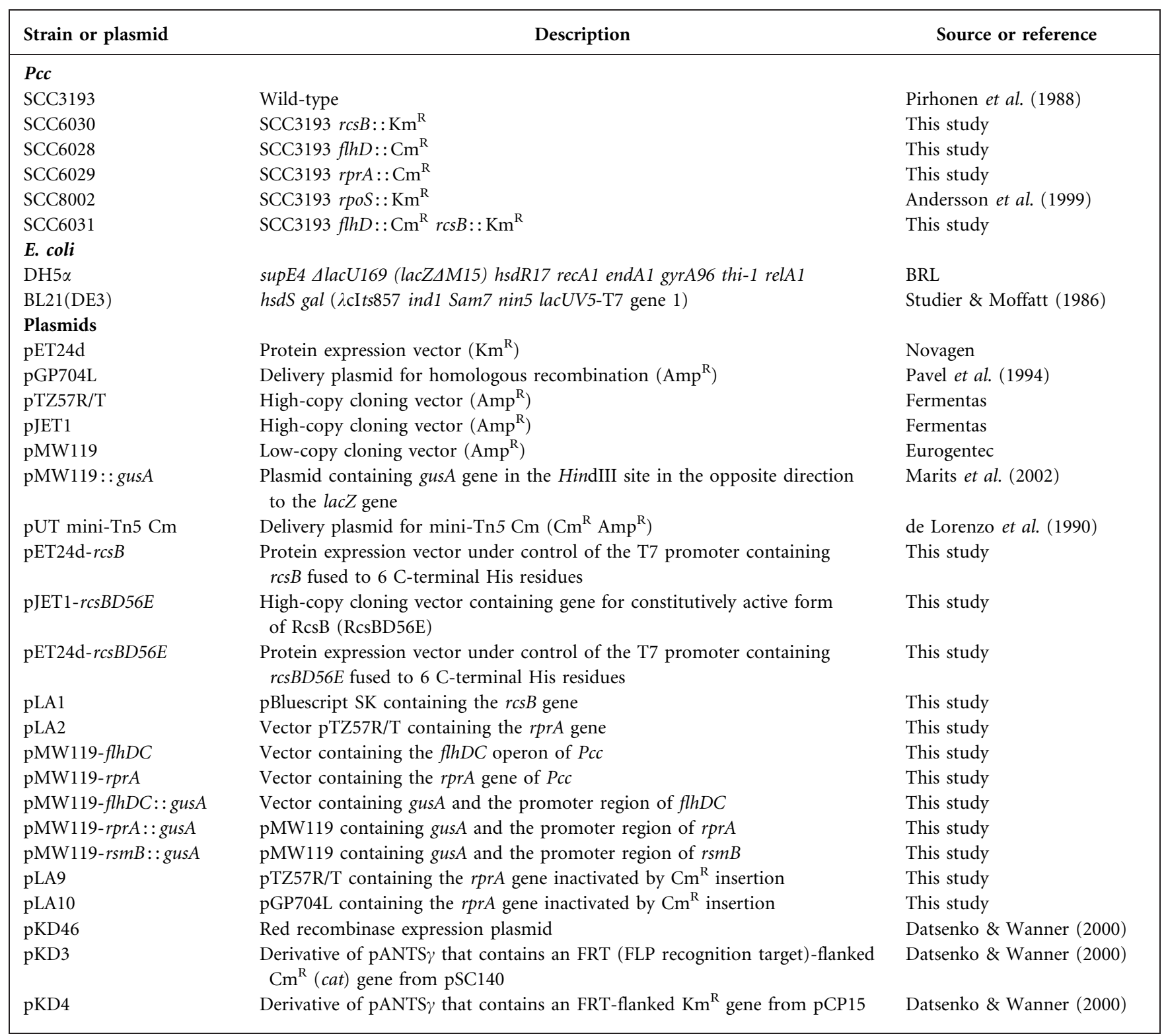

(SCC6031) was generated using the $r c s B:: K m$ mutant (SCC6030) background and the same methods and primers as described above.

To obtain a knockout mutant of rprA, plasmid pLA2 (pTZ57R/T containing a PCR fragment amplified with primers rprAY and rprAA2) was digested with restriction enzyme BplI (Fermentas) to disrupt the $r p r A$ gene sequence at position +25 relative to the transcription start site. The cat gene, obtained from plasmid pUT mini-Tn5 $\mathrm{Cm}$ as a BamHI fragment, was cloned into BplI-digested pLA2 to create pLA9. The disrupted $r p r A$ fragment was amplified from pLA9 using primers rprAY and rprAA2 and cloned into the EcoRV-digested vector, pGP704L, to yield pLA10. The rprA-negative mutant (SCC6029) was created using the $\lambda$ Red system (Datsenko \& Wanner, 2000), with primers rprAY and rprAA2 and pLA10 as a template.

All of the mutants generated were verified by PCR amplification.

Enzyme assays. For $\beta$-glucuronidase (GusA) assays, cells were grown in M9 minimal medium supplemented with $0.4 \%$ glycerol with or without the addition of PGA. GusA activity was measured at 6,8 and $10 \mathrm{~h}$ after inoculation. In the case of pMW119-flhDC::gusA and pMW119-rprA:: gusA constructs, GusA activity was measured with $p$ nitrophenyl $\beta$-D-glucuronide as a substrate (Novel et al., 1974). The degradation product, $p$-nitrophenol $(p \mathrm{NP})$, was detected at $405 \mathrm{~nm}$, and the specific activity of GusA was expressed as nmol $p$ NP liberated $\min ^{-1}$ per $\mathrm{OD}_{600}$ unit. In the case of the pMW119-rsmB::gusA construct, GusA activity was measured with 4 -methylumbelliferyl $\beta$-Dglucuronide (MUG; DUCHEFA Biochemie) as substrate. Five microlitres of sample was taken at each time point and permeabilized in $90 \mu \mathrm{l}$ CTAB buffer $(0.05 \%$ hexadecyltrimethylammonium bromide, $0.27 \%$ $\beta$-mercaptoethanol and $1 \mathrm{mM}$ EDTA in $50 \mathrm{mM}$ sodium phosphate buffer $\mathrm{pH} 7)$ for $10 \mathrm{~min}$. After addition of MUG $\left(15 \mu \mathrm{mol} \mathrm{l}^{-1}\right)$ to the permeabilized cells, accumulation of the florescent product 4methylumbelliferone (MU) was measured with a fluorescence spectophotometer (GENios Plus; Tecan) using an excitation filter of $360 \mathrm{~nm}$ and an emission filter of $465 \mathrm{~nm}$. The slope of relative fluorescence units per minute was calculated. GusA activity of the 
Table 2. Oligonucleotide primers used in this study

\begin{tabular}{|c|c|}
\hline Name & Sequence $\left(5^{\prime}-3^{\prime}\right)^{*}$ \\
\hline rcsBP1 & CCTAAACGTAATTATTGCCGACGACCATCCCATTGTCCTTTGTGTAGGCTGGAGCTGCTTC \\
\hline rcsBP2 & TTCGCCAACCACATTGACCCATTCAATTTGCTCAAGTGATTTTTTGATGCCAACATATGAATATCCTCCTTA \\
\hline RcsBHindIII & AAGCTTGTCGACTTGTGTTGCGCCGCC \\
\hline RcsBNcoI & 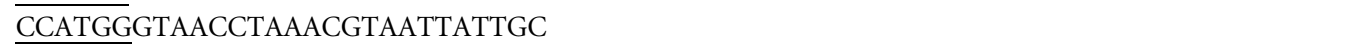 \\
\hline flhD1 & $\overline{\text { CATCACGCGGAGAATTCG }}$ \\
\hline RcsBD56E & CCCGGCATGGATAACTCGGTGAT \\
\hline rcsBalg & CCTAAAGGGCAGCAAGGTAG \\
\hline rcsCend & TGATTCTGGTGGTTGACGA \\
\hline flhD2 & CCAGATACAGGTTGGTTCAT \\
\hline rprAFP1 & TCATTGACAAACAGTAGGTTAA \\
\hline rprAFP2 & ATCATTTCTCTAATGCATCAATA \\
\hline rsmBpA & TTCCTAAAACAATCCGAGTG \\
\hline rsmBpY & TTTCTGGCCTTAACCCGTTA \\
\hline PROS & AATAAAAATTAGTCATCATTACC \\
\hline PRIMEX2 & ACTGAGGTATCGTCATCTC \\
\hline flhDup & AAAGATGTGATCAGGAAATG \\
\hline flhCA & TTACAGGCTCAGACTGCGTG \\
\hline flhDP1 & CGAACTGGGCGATATGGTCTATCACCTAACTTATGTTTTAAACATAGCCGTGTAGGCTGGAGCTGCTTC \\
\hline flhDP2 & AGATTAATGTCATAAATGTGTTTGAGTAATTCAGAGGTACCCATATTTCCATATGAATATCCTCCTTAG \\
\hline rprAY & AACCGCAGAACCTCCTCTCTG \\
\hline rprAA2 & GTCCCCATTGTTTTGCCTTC \\
\hline flhDFw & GCGCAACGCTTAATTAATGATGA \\
\hline flhDRev & AGTTGCATCAAGATATCTGCCATCTC \\
\hline ffhFw & CGTATCGCATCACGCATTCT \\
\hline ffhRev & TCCAGGAAATCGGTCAAATC \\
\hline
\end{tabular}

*Sites designed for restriction enzymes are underlined.

sample was expressed as nmol substrate hydrolysed $\mathrm{h}^{-1} \mathrm{ml}^{-1}$ per $\mathrm{OD}_{600}$ unit, based on a standard curve of MU concentrations. All GusA assays were performed using three technical replications.

To perform semiquantitative agarose plate assays of extracellular protease (Prt) production, cells were grown overnight in M9 medium and washed and suspended in the same medium. Drops of cell suspensions containing $\sim 10^{6}$ cells were dotted onto milk-containing agar plates (Chatterjee et al., 1995), and the plates were photographed after 3 days of growth at $30{ }^{\circ} \mathrm{C}$. The diameter of the halo produced was considered to be proportional to the amount of enzyme secreted. All assays were performed at least five times.

To quantify the activity of pectate lyase and cellulase, cells were grown on M9 minimal medium supplemented with $0.2 \%$ PGA. Three replications were used to measure enzyme activities as described previously (Pirhonen et al., 1991).

Real-time RT-PCR. Wild-type cells harbouring the control plasmid, pMW119, or a plasmid overexpressing $r p r A$, pMW119-rprA, were grown overnight on milk-containing agar plates at $30{ }^{\circ} \mathrm{C}$. Cells were harvested and total RNA was isolated using the NucleoSpin RNA II kit (Macherey-Nagel). An additional treatment with DNase I (Fermentas) was performed according to the manufacturer's protocol. Real-time RT-PCR was performed using the Verso SYBR Green 1-Step QRT-PCR ROX kit (Thermo Scientific) using the Applied Biosystems 7900 HT real-time thermal cycler. Each reaction contained 2 ng total RNA and $100 \mathrm{nM}$ forward and reverse primers. The sequences of primers used are given in Table 2.

The PCRs were run using the following programme: $50{ }^{\circ} \mathrm{C}$ for $15 \mathrm{~min}, 95^{\circ} \mathrm{C}$ for $15 \mathrm{~min}$ to inactivate reverse transcriptase, and 40 cycles of $95{ }^{\circ} \mathrm{C}$ for $15 \mathrm{~s}$ and $60{ }^{\circ} \mathrm{C}$ for $30 \mathrm{~s}$. Following PCR amplification, the reactions were subjected to temperature ramping to create the dissociation curve, measured as changes in fluorescence measurements as a function of temperature, by which the nonspecific products can be detected. The dissociation programme was $95{ }^{\circ} \mathrm{C}$ for $1 \mathrm{~min}, 60{ }^{\circ} \mathrm{C}$ for $15 \mathrm{~s}$, followed by a $2 \%$ ramp from $60{ }^{\circ} \mathrm{C}$ to $95{ }^{\circ} \mathrm{C}$. Results are presented as mean expression ratios calculated using the $2^{-\Delta \Delta C_{\mathrm{t}}}$ method as described by Livak \& Schmittgen (2001). The ffh gene (encoding a signal recognition particle involved in targeting and integration of inner-membrane proteins) was used for normalization of reverse transcriptase real-time PCR data according to Takle et al. (2007). All RNA isolations and reverse transcriptase real-time PCRs were performed using three replications.

\section{RESULTS}

\section{The response regulator, $\mathrm{Rcs} B$, binds to the promoters of flhDC, rprA and rsmB}

We previously demonstrated that an $r c s B$-negative mutant expressed higher levels of PCWDE than wild-type Pcc (Andresen et al., 2007). To further investigate the regulatory effect of RcsB on PCWDE expression in $P c c$, the promoter regions of the prtW, pehA, pelB, pelC and $c e l V 1$ genes were analysed for RcsB-binding sites. Using the Virtual Footprint program (see Methods; Münch et al., 2005), regions upstream of these genes were not found to 
contain any putative RcsB-binding sites. Subsequently, the genome of $\mathrm{Pba}$ was analysed, and 16 putative RcsB-binding sites were found associated with promoter regions of 16 genes (see Supplementary Table S1, available with the online version of this paper). Of these genes, RcsB-binding sites in $f l h D C$ and $r p r A$ were previously characterized in $E$. coli, and $r s m B$ codes for a global regulator of PCWDE in Pcc (Francez-Charlot et al., 2003; Liu et al., 1998; Majdalani et al., 2002). Therefore, flhDC, $r p r A$ and $r s m B$ were selected for further analysis.

To identify the DNA-binding sites for RcsB in the promoter regions of flhDC, $r p r A$ and $r s m B$, DNase I footprinting assays were performed using purified, histidine-tagged RcsB. The DNA footprinting assay of $f l h D$ upstream sequences $(-374$ to -171$)$ revealed an RcsB-binding site that protected a region spanning $26 \mathrm{bp}$ from -262 to -236 (Fig. 1a). In the rprA promoter, bp -124 to +35 and bp -51 to -27 were protected by binding of RcsB (Fig. 1b). In contrast, neither the $r s m B$ promoter, nor the promoter of an extracellular protease, PrtW, used as a negative control, were protected from DNase I cleavage in the presence of histidine-tagged RcsB (data not shown). The putative RcsB-binding site in the $r \operatorname{sm} B$ promoter was identified using purified histidinetagged RcsBD56E. Replacement of conserved aspartate residue in position 56 with glutamic acid is known to make the RcsB protein constitutively active in E. coli, without needing RcsC, RcsF or RcsA for its activity (Gupte et al., 1997). DNase I footprinting revealed that the protected regions extended from position -192 to position -211 and from position -213 to position -230 upstream of the start codon of $r s m B$ (Fig. 1c). The prt $W$ promoter fragment, used as a negative control, was not protected from DNase I cleavage in the presence of histidine-tagged RcsBD56E (data not shown). The nucleotide sequences of the protected regions identified in this study are similar to known RcsB target sites (Fig. 1d).

\section{RcsB modulates expression of flhDC, rprA and rsmB in PcC}

To further characterize the influence of RcsB binding on flhDC, $r p r A$ and $r s m B$ expression, fusions of gusA with flhDC, $r p r A$ and $r s m B$ were created, and gene expression for the three constructs was compared between the wild-type strain and an $r c s B$-negative mutant. In the $r c s B$-negative mutant, a fourfold increase in expression of the flhDC: : gusA fusion was detected, while only low levels of expression of the rprA::gusA fusion were detected compared to the wild-type strain. These results indicate that $f l h D C$ and $r p r A$ are directly regulated by RcsB in $P c c$, with RcsB positively regulating rprA expression, and negatively affecting flhDC expression.

The expression of the $r s m B::$ gusA fusion was increased 1518 -fold in an $r c s B$-negative mutant as compared to the wild-type strain (Fig. 2a). We also found that the effect of the $r c s B$ mutation on $r s m B::$ gus $A$ expression is mediated through $f l h D C$ in these conditions. We compared the expression of rsmB:: gusA fusion in an $f h D C$-negative mutant and in an $f h D C / r c s B$ double-negative mutant. No significant differences were found in $r s m B:: g u s A$ expression between these strains in M9 minimal salts medium supplemented with glycerol throughout the entire growth curve (data not shown). When the same mutants were tested for $r s m B:: g u s A$ expression in M9 minimal salts medium supplemented with PGA, GusA activity in $\mathrm{flhDC/}$ $r c s B$ double-negative mutant was similar to that in $f l h D C$ negative strain, except at one time point $(6 \mathrm{~h}$ after inoculation) in the early exponential growth phase, where the $f l h D C / r c s B$ double mutant expressed 3.4 times higher GusA activity than the flhDC-negative strain (Fig. 2b).

\section{RcsB modulates expression of PCWDE through fIhDC}

To determine whether the Rcs phosphorelay modulates expression of PCWDE by regulating flhDC, flhDC mutants were created in Pcc strain SCC3193. As shown in Fig. 3, inactivation of $f l h D C$ resulted in a dramatic decrease in levels of pectate lyases, cellulase and protease compared to the wildtype strain. When expression of $f h D C$ was restored using a low-copy plasmid (pMW119-flhDC), expression of PCWDE increased in the wild-type strain, and was restored in the flhDC-negative strain. An $r c s B$ null mutation in a wild-type background was also previously shown to increase expression of PCWDE (Andresen et al., 2007). To investigate whether $r c s B$ inactivation could restore expression of PCWDE in an flhDC mutant, enzyme production in an $f l h D C / r c s B$ double mutant was analysed. The double mutant did not regain enzyme production when compared to the $r c s B$ mutant strain, indicating that the effect of $r c s B$ inactivation on expression of PCWDE is dependent on FlhDC.

\section{Overexpression of RprA RNA modulates rpoS- independent expression of an extracellular protease and has only a minor effect on expression of pectate lyases and cellulase}

As shown in Fig. 2(a), transcription of the rprA gene is positively regulated by RcsB. To assess the capacity of RprA RNA to regulate expression of PCWDE, an rprA-negative mutant was constructed and enzyme assays were performed. The activity of pectate lyases, cellulase and protease in both mutant and wild-type strains was detected. Inactivation of $r p r A$ did not affect expression of these enzymes (Fig. 3). When rprA was overexpressed in the wild-type strain, protease activity increased (Fig. 3). Cellulase activity of the strain overexpressing $r p r A$ was 1.7 times higher than that of the wild-type strain, while activity of pectate lyase was only slightly elevated (Fig. 3).

RprA RNA was initially discovered and characterized in $E$. coli as a positive regulator of rpoS translation (Majdalani et al., 2001). The effect of RpoS on RprA RNA modulation of PCWDE in $P c c$ was therefore analysed using plate assays. As shown in Fig. 4, overexpression of rprA in an rpoS-negative 
(a)

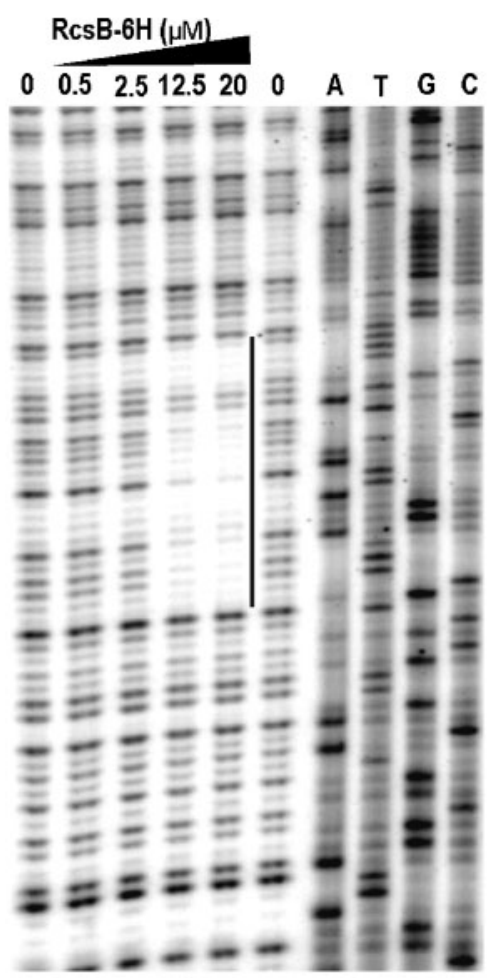

(b)

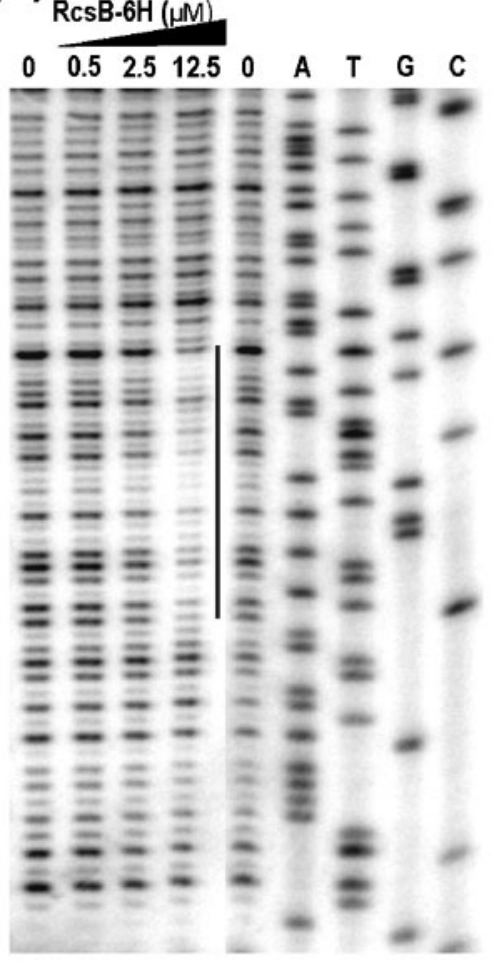

(c)

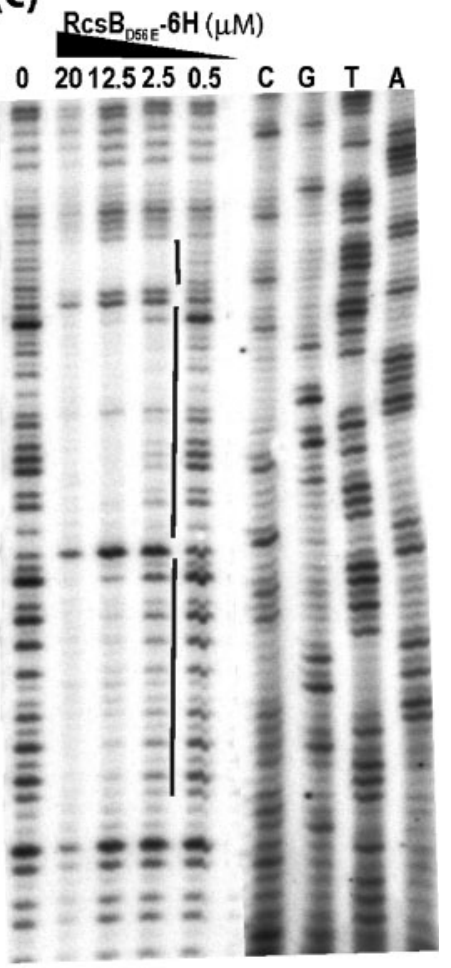

(d)

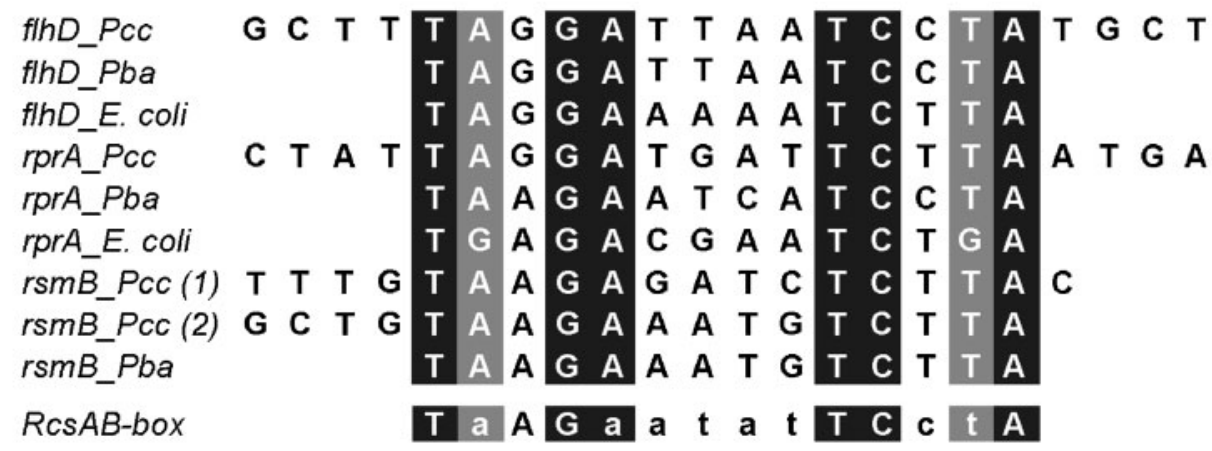

Fig. 1. $(a-c)$ DNase I footprinting assays of histidine-tagged RcsB, histidine-tagged RcsBD56E, and promoter regions of flhDC (a), rprA (b) and rsmB (c). DNA probes labelled on the coding strand were incubated with varying concentrations (0$20 \mu \mathrm{M}$ ) of histidine-tagged RcsB (RcsB-6H) or histidine-tagged RcsBD56E (RcsB D56E $^{-6 H i s)}$ prior to treatment with DNase I. Sequencing gels are shown and the letters $\mathrm{A}, \mathrm{T}, \mathrm{G}$, and $\mathrm{C}$ indicate the DNA sequences of fragments digested by DNase I. (d) The RcsB-binding sites of the $f / h D C, r p r A$ and $r s m B$ promoters of $P c c$ are aligned with known RcsB-binding sequences in $E$. coli, predicted RcsB-binding sequences in Pba, as well as the RcsAB box described by Wehland \& Bernhard (2000). Lowercase letters in the RcsAB box indicate nucleotides that have a conservation rate of $50-70 \%$ relative to the consensus sequence, and upper-case letters indicate a conservation rate of $>70 \%$.

mutant stimulated protease expression, indicating that the effect of $r p r A$ on protease synthesis is independent of $r p o S$.

\section{Regulation of PCWDE by FIhDC and RprA RNA does not overlap}

The results shown in Fig. 3 demonstrate that both $f l h D C$ and $r p r A$ are able to enhance protease expression in $P c c$. To determine whether flhDC and $r p r A$ can functionally replace each other, an $f l h D C$ overexpression construct was introduced into an rprA-negative mutant and an $\operatorname{rprA}$ overexpression construct was introduced into a $f h D C$ negative mutant. When $f l h D C$ was exogenously expressed from pMW119-flhDC in a rprA-negative background, protease expression was increased. However, when $r p r A$ was exogenously expressed from pMW119-rprA in a 
(a)

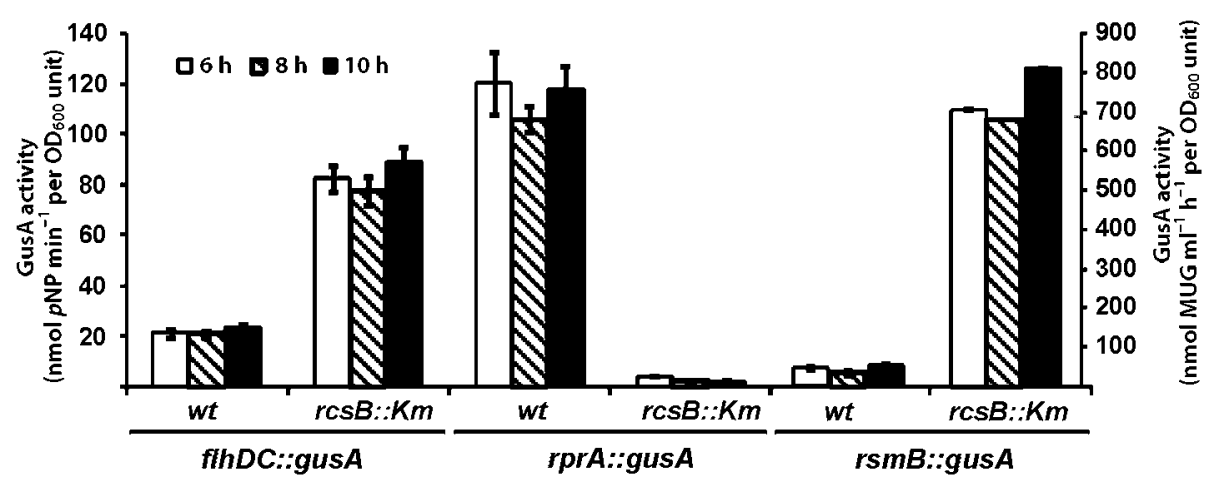

(b)

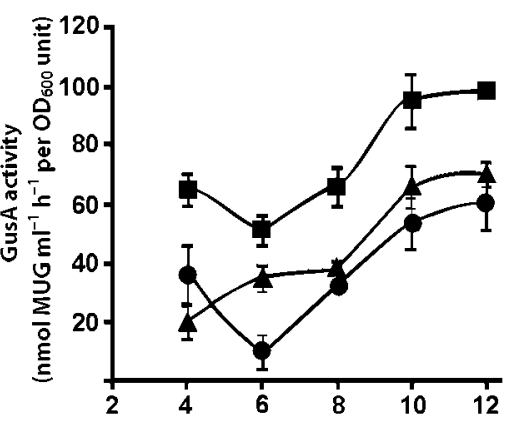

Fig. 2. Expression of promoters fused with reporter gene gus $A$ coding for $\beta$-glucuronidase (Gus $A$ ). Gus $A$ activity was measured at different times after inoculation and experiments were performed in triplicate. Error bars represent SD. (a) Expression of $f / h D C::$ gus $A, \operatorname{rpr} A::$ gus $A$ and $r s m B::$ gus $A$ fusions was measured in wild-type (wt; SCC3193) and rcsBnegative ( $r c s B:: K m$; SCC6030) strains grown in M9 minimal medium supplemented with glycerol. In the case of the $f / h D C$ and rprA promoter constructs (pMW119-flhDC:: gusA and pMW119-rprA::gusA) GusA activity was measured with $p$-nitrophenyl $\beta$-D-glucuronide as a substrate (left axis), whereas in the case of the rsmB promoter fusion (pMW119-rsmB::gusA) GusA activity was measured with 4-methylumbelliferyl $\beta$-D-glucuronide as a substrate (right axis); (b) Expression of $r s m B:: g u s A$ fusion in wild-type $(\boldsymbol{\square}), f / h D C$-negative mutant $(\bullet)$ and $f / h D C / r c s B$ double mutant $(\boldsymbol{\Delta})$ in minimal medium supplemented with $0.2 \%$ PGA.

flhDC-negative background, protease expression did not increase (Fig. 5). To determine whether the positive effect of $r p r A$ overexpression on protease expression is dependent on an increase in $f l h D C$ expression, reverse transcription real-time PCR was used to evaluate flhDC mRNA levels in a wild-type strain, an $r c s B$-negative mutant, and a strain overexpressing rprA. In the $r c s B$-negative mutant, flhDC mRNA levels were $1.36 \pm 0.15$ times higher than in the wild-type strain. In contrast, overexpression of rprA decreased flhDC mRNA levels compared with wild-type ( $r p r A$ overexpression to wild-type ratio $0.84 \pm 0.22$ ). These results demonstrate that activation of protease transcription associated with overexpression of $r p r A$ is not caused by increased $f h D C$ transcription.

\section{DISCUSSION}

Genes directly regulated by the Rcs phosphorelay response regulator, RcsB, have been shown to have RcsB-binding sites in their promoters (Wehland \& Bernhard, 2000). However, no RcsB-binding sites were identified in any of the PCWDE promoters analysed, although sequences similar to RcsB sites were found in the regulatory regions of the $r s m B$, flhDC and rprA genes (Supplementary Table S1). In vitro, RcsB was shown to directly bind the promoter regions of $f l h D C, r p r A$ and $r s m B$. The regulatory regions of $f h D C$ and $r p r A$ were bound by the unphosphorylated form of RcsB, whereas the $r s m B$ promoter was bound only by RcsBD56E, a constitutively active form of RcsB (Gupte et al., 1997). These results indicate that the binding sites of RcsB in the $r s m B$ promoter region may have lower affinity for unphosphorylated RcsB when compared to the binding sites in the $r p r A$ and $f l h D C$ promoters. This would suggest that $r s m B$ is directly regulated by RcsB in response to a signal activating the Rcs phosphorelay, whereas flhDC and rprA are regulated by RcsB even in the absence of the signal.

In vivo, RcsB positively affected $r p r A$ transcription and negatively affected $f l h D C$ and $r s m B$ transcription (Fig. 2a), demonstrating that direct transcriptional regulation of $r p r A$ and $f l h D C$ expression by the Rcs phosphorelay is not exclusive to E. coli and Salmonella (Francez-Charlot et al., 2003; Majdalani et al., 2002; Wang et al., 2007). The flagella master regulator, FlhDC, has been previously shown to positively regulate RsmB RNA levels in Pcc (Cui et al., 2008; Fig. 2b); thus RcsB may regulate transcription of $r s m B$ both directly and indirectly through modulating the expression of $f l h D C$. Our experiments with an $f l h D C$-negative mutant and an $f l h D C / r c s B$ double-negative mutant indicate that in minimal medium the effect of RcsB on $r s m B$ transcription is mediated by FlhDC. When these mutants were grown on minimal medium supplemented with PGA the expression of the $r s m B:: g u s A$ fusion was 3.4 times higher in the $f l h D C /$ $r c s B$ double-negative mutant than in the $f h D C$-negative mutant at one time point in the early exponential growth phase (Fig. 2b). These results indicate that $r s m B$ expression is mainly regulated by RcsB via $f h D C$ also in the presence of PGA, but can be directly regulated by RcsB at certain stages of growth. Why the difference in $r s m B::$ gusA expression between $f l h D C$-negative and $f l h D C / r c s B$ double-negative mutant appears only in the presence of PGA and at a certain time is currently under investigation.

Our results are consistent with previous studies that have shown that the flagella master regulator, FlhDC, contri- 
(a)

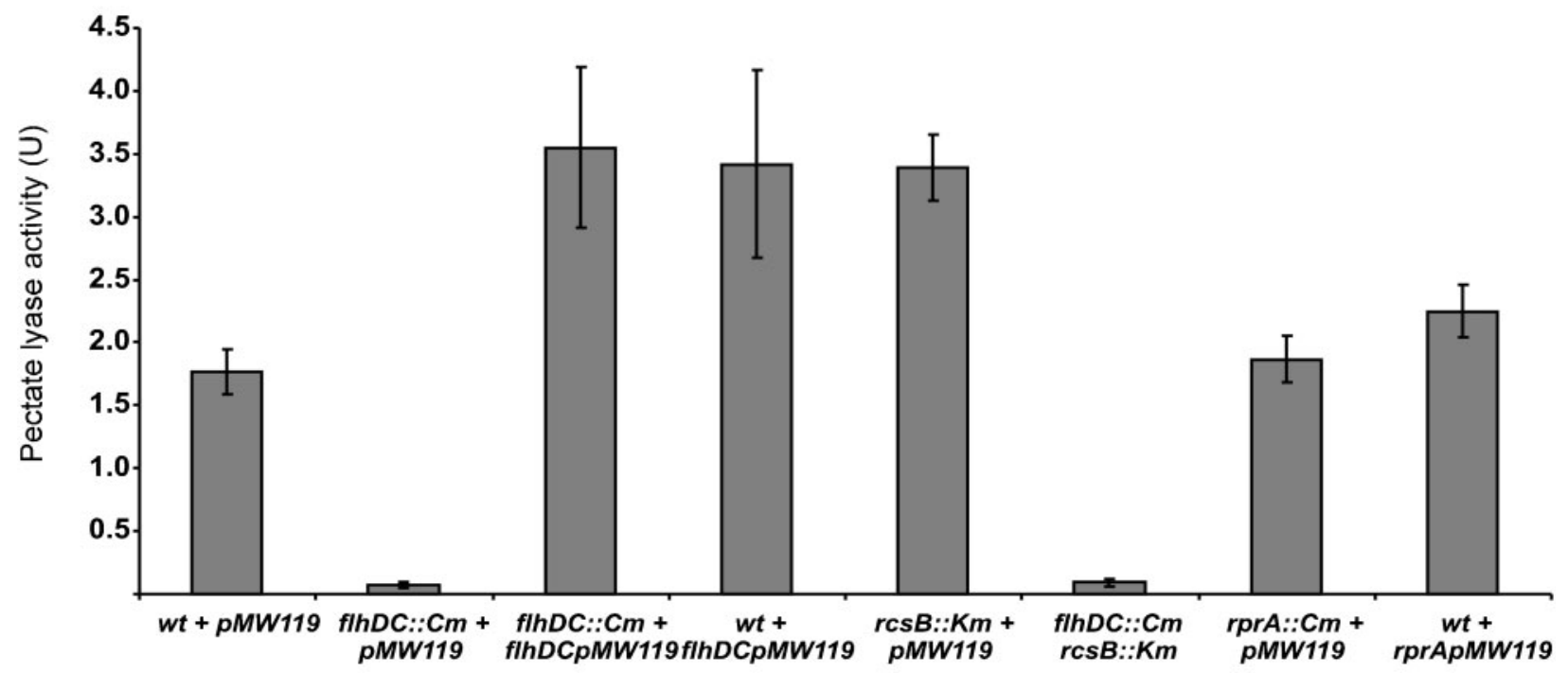

(b)

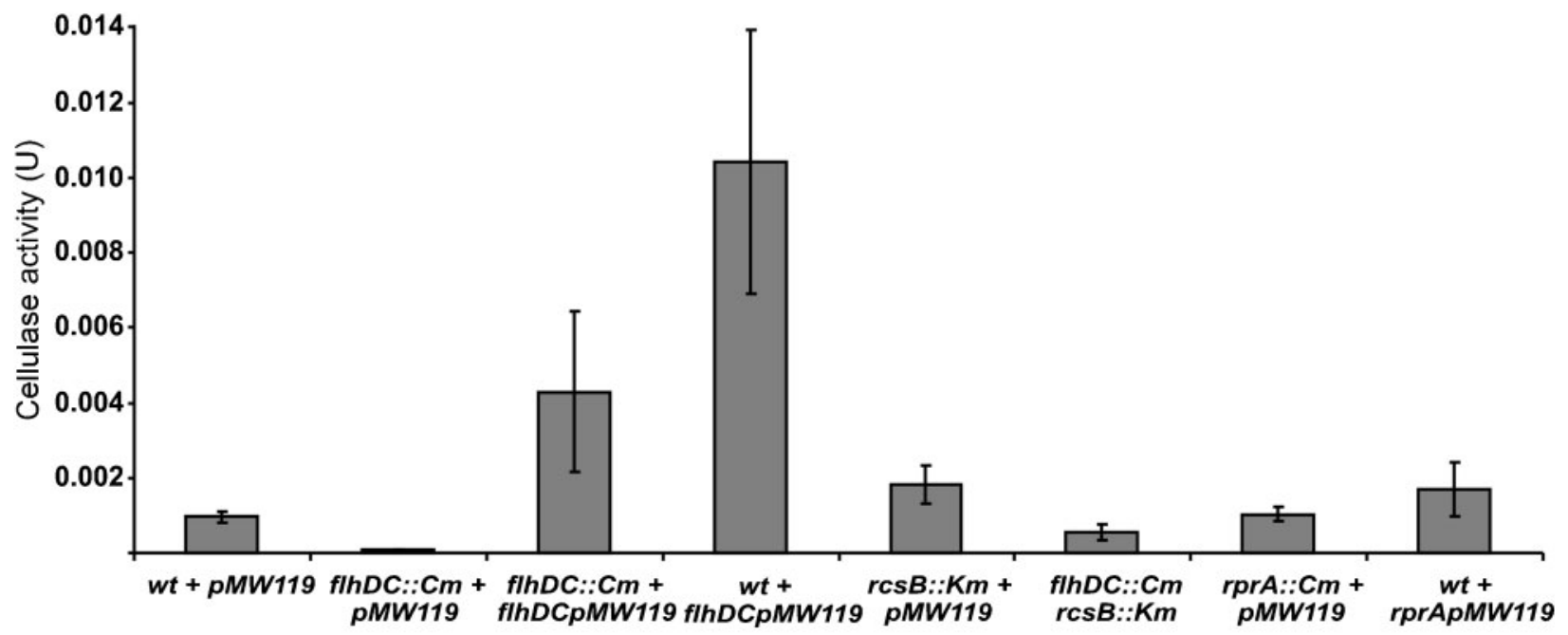

(c)

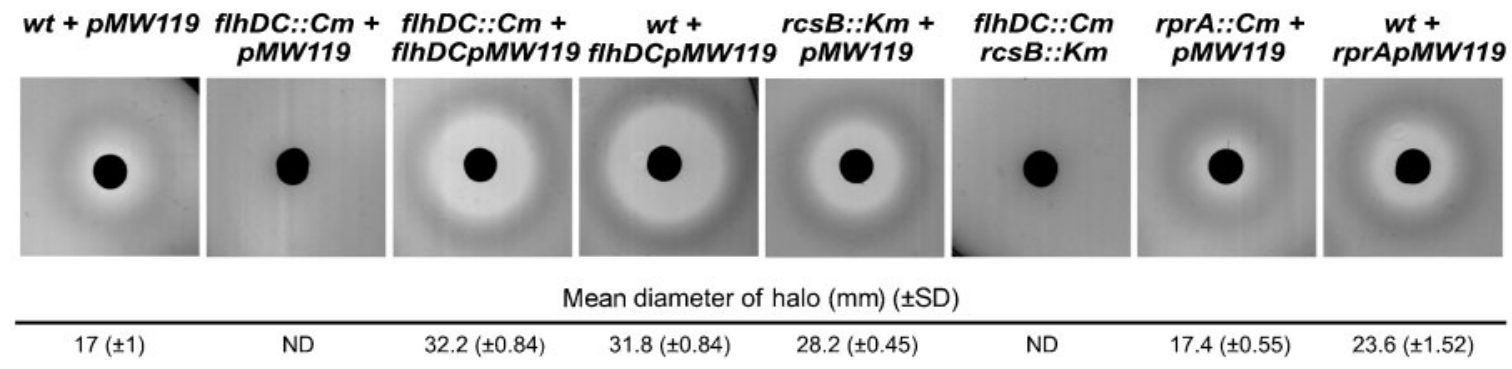

Fig. 3. Influence of FlhDC and RprA RNA on the expression of PCWDE. (a, b) For assays of pectate lyases (a) and cellulase (b), enzyme activities were measured $10 \mathrm{~h}$ after inoculation and the means \pm SD of three independent experiments are shown. (c) Production of protease was observed after 3 days and the diameter of the halo (in $\mathrm{mm}$ ) was measured from at least five independent experiments. ND, not detectable; wt, wild-type strain SCC3193; flhDC:: Cm, flhDC-negative strain SCC6028; $r c s B:: K m, r c s B$-negative strain SCC6030; flhDC::Cm rcsB::Km, flhDC- and rcsB- negative double mutant; rprA::Cm, rprA-negative strain SCC6029; fIhDCpMW119, flhDC overexpression plasmid; rprApMW119, rprA overexpression plasmid; pMW119, control vector. 


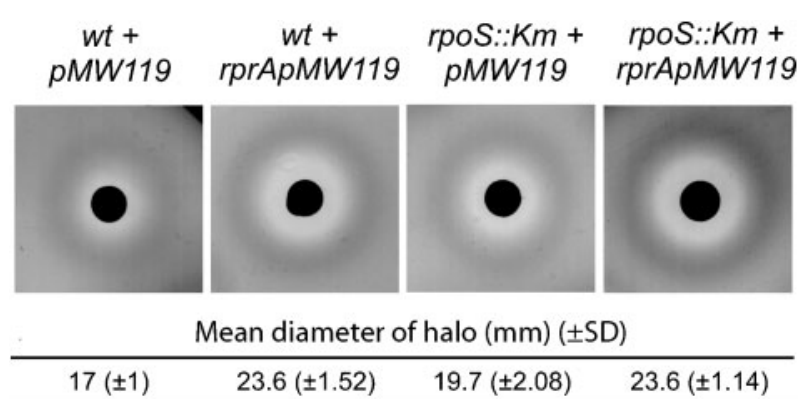

Fig. 4. Effect of rprA overexpression on protease expression in wild-type (wt; strain SCC3193) and RpoS-mutant (rpoS:: Km; strain SCC8002) strains. Wild-type containing vector pMW119 was used as a control ( $w t+p M W 119)$. Assay plates were photographed after 3 days and the diameter of the halo (in $\mathrm{mm}$ ) was measured from at least five independent experiments.

butes to the virulence of $P c c$ (Cui et al., 2008). The results of this study demonstrate that inactivation of $r c s B$ in an flhDC-negative mutant does not restore expression of PCWDE. Since the flhDC mutant and the $f l h D C / r c s B$ double mutant exhibited the same phenotype, a model where the Rcs phosphorelay targets PCWDE genes indirectly via FlhDC is supported. Cui et al. (2008) reported that FlhDC activates expression of PCWDE indirectly by reducing the activity of the Rsm regulatory system. Based on these data and our results, we hypothesize that the Rcs phosphorelay regulates the expression of PCWDE by modulating the activity of the Rsm system directly (only in certain conditions) by regulating $r \mathrm{smB}$ expression and indirectly through flhDC (Fig. 6). Furthermore, our results suggest that the effect of the Rcs phosphorelay on motility of $P c c$ presented in our previous paper (Andresen et al., 2007) was most likely due to elevated expression of $f l h D C$ in the rcs-negative mutants.

We were also interested in dissecting the contribution of $r p r A$ to expression of PCWDE in Pcc. In contrast to flhDC,

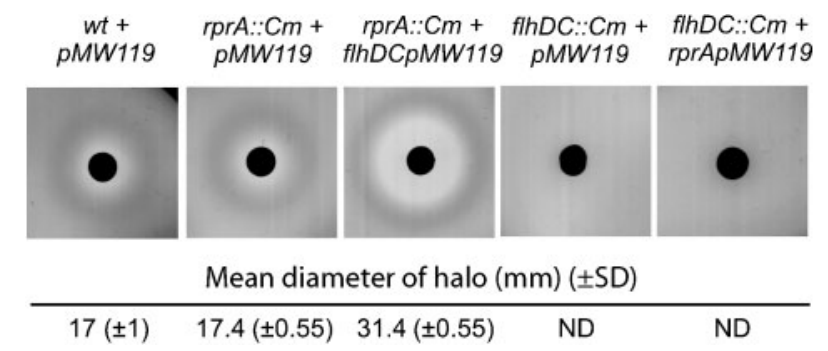

Fig. 5. Effects of overexpressing $f / h D C$ and $r p r A$ on protease expression in rprA-negative (rprA::Cm; strain SCC6029) and flhDC-negative (flhDC::Cm; strain SCC6028) mutants, respectively. Assay plates were photographed after 3 days of incubation and the diameter of the halo (in $\mathrm{mm}$ ) was measured from at least five independent experiments. ND, not detectable.

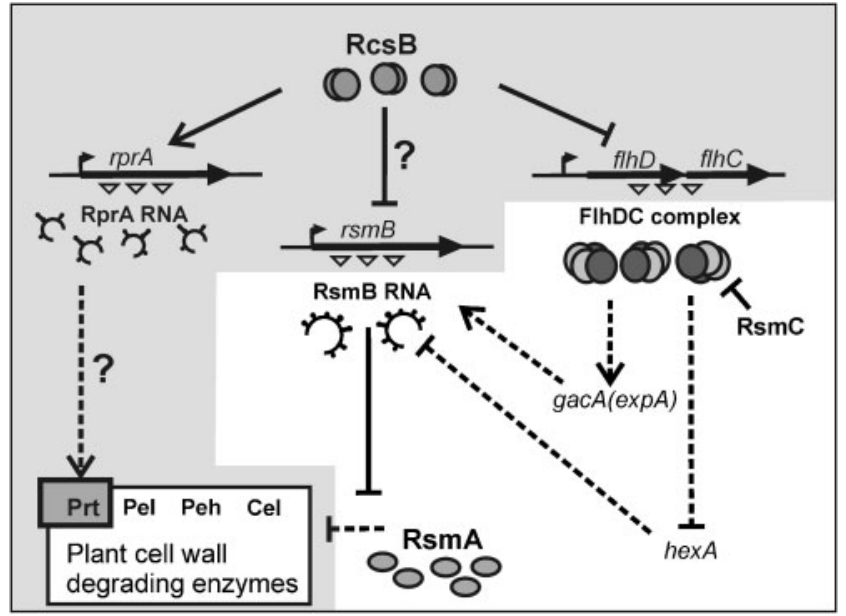

Fig. 6. A proposed model for regulated expression of PCWDE by the Rcs phosphorelay in Pcc. The steps of the model indicated on the shaded background are based on data from this study. RcsB affects the expression of PCWDE by directly binding the promoters of $r p r A, r s m B$ and $f / h D C$. RcsB positively controls the transcription of small regulatory RprA RNA and negatively affects the transcription of $r s m B$ and flhDC. A question mark indicates that the exact conditions in which these interactions become important in PCWDE regulation are not yet known. Expression of FlhDC activates gacA expression and represses hexA expression, which in turn increases the level of RsmB RNA in Pcc (Cui et al., 2008) and decreases the pool of free RsmA, resulting in enhanced expression of PCWDE (Liu et al., 1998). Not all of the molecular mechanisms encompassed by this model are fully characterized (indicated with dashed lines). Furthermore, RsmC acts as an antiFlhDC factor by binding to FlhDC and interfering with FlhDC action (Chatterjee et al., 2009).

which has a significant effect on expression of PCWDE, only increased expression of an extracellular protease was detected in response to exogenous expression of $r p r A$ in the wild-type strain. Our data further exclude the possibility that RprA RNA is dependent on $f l h D C$ for regulation of protease expression. Moreover, although exogenous expression of rprA did not enhance flhDC mRNA levels as detected by reverse transcription real-time PCR assays, it is intriguing to hypothesize that RprA RNA may affect the translation or proteolysis of FlhDC.

In E. coli and Salmonella, RprA RNA positively affects translation of RpoS by direct interaction with rpoS mRNA, which is currently the only known target for RprA RNA (Jones et al., 2006; Majdalani et al., 2001, 2002). In both organisms RprA RNA has an effect on rpoS translation in the absence of DsrA RNA (another RNA regulator of $r p o S$ translation) under conditions of osmotic shock (Jones et al., 2006; Majdalani et al., 2001). The results of these studies indicate that RprA RNA needs specific conditions for its activity on rpoS translation. In this study, rprA overexpression was shown to affect protease expression, suggesting that transcription of $r p r A$ could stimulate 
protease expression in the wild-type strain under physiological conditions where the expression level of $r p r A$ is elevated. Correspondingly, in E. coli, rprA expression has been shown to increase when the Rcs phosphorelay is artificially activated (Majdalani et al., 2005). Further studies are needed to address the role of RprA RNA as a regulator of protease synthesis in $P c c$ under conditions that activate the Rcs phosphorelay.

In the current study, rpoS was not necessary for protease expression induced by RprA RNA (Fig. 4), and this is the first evidence for a role for RprA RNA that is independent of RpoS. It remains unclear whether RprA RNA directly binds the target protease mRNA, or whether RprA RNA indirectly induces protease expression via another regulatory gene.

In summary, we have demonstrated that the Rcs phosphorelay mediates expression of PCWDE mainly through the direct binding of RcsB to the flhDC promoter, which in turn causes a subsequent decrease in $r s m B$ transcription. Another way to repress $r s m B$ transcriptsion is by direct binding of $R \operatorname{csB}$ on the promoter region of $r s m B$, but the conditions in which that becomes important in PCWDE regulation are not yet clear. Lower RsmB RNA levels increase the levels of active RsmA in the cell, which effectuates the degradation of PCWDE gene mRNAs (Liu et al., 1998; Fig. 6). Further study is needed to identify the direct target genes for FlhDC in the regulatory pathway controlling expression of PCWDE genes, the physiological conditions that stimulate the regulatory role of RprA, and the complex relationship between these regulatory factors.

\section{ACKNOWLEDGEMENTS}

This research was supported by the Estonian Science Foundation (GLOMR7082 and SF0180088s08). We thank Dr T. Alamäe for critical reviewing of the manuscript.

\section{REFERENCES}

Andersson, R. A., Kõiv, V., Norman-Setterblad, C. \& Pirhonen, M. (1999). Role of RpoS in virulence and stress tolerance of the plant pathogen Erwinia carotovora subsp. carotovora. Microbiology 145, 3547-3556.

Andresen, L., Kõiv, V., Alamäe, T. \& Mäe, A. (2007). The Rcs phosphorelay modulates the expression of plant cell wall degrading enzymes and virulence in Pectobacterium carotovorum ssp carotovorum. FEMS Microbiol Lett 273, 229-238.

Bell, K. S., Sebaihia, M., Pritchard, L., Holden, M. T., Hyman, L. J., Holeva, M. C., Thomson, N. R., Bentley, S. D., Churcher, L. J. \& other authors (2004). Genome sequence of the enterobacterial phytopathogen Erwinia carotovora subsp. atroseptica and characterization of virulence factors. Proc Natl Acad Sci U S A 101, 11105-11110.

Burr, T., Barnard, A. M. L., Corbett, M. J., Pemberton, C. L., Simpson, N. J. L. \& Salmond, G. P. C. (2006). Identification of the central quorum sensing regulator of virulence in the enteric phytopathogen, Erwinia carotovora: the VirR repressor. Mol Microbiol 59, 113-125.
Carballes, F., Bertrand, C., Bouche, J. P. \& Cam, K. (1999). Regulation of Escherichia coli cell division genes $f t s A$ and $f t s Z$ by the two-component system $r c s C$-rcsB. Mol Microbiol 34, 442-450.

Chatterjee, A., Cui, Y., Liu, Y., Dumenyo, C. K. \& Chatterjee, A. K. (1995). Inactivation of $r s m A$ leads to overproduction of extracellular pectinases, cellulases, and proteases in Erwinia carotovora subsp. carotovora in the absence of the starvation/cell density-sensing signal, $\mathrm{N}$-(3-oxohexanoyl)-L-homoserine lactone. Appl Environ Microbiol 61, 1959-1967.

Chatterjee, A., Cui, Y. Y. \& Chatterjee, A. K. (2009). RsmC of Erwinia carotovora subsp. carotovora negatively controls motility, extracellular protein production, and virulence by binding FlhD and modulating transcriptional activity of the master regulator, FlhDC. J Bacteriol 191, 4582-4593.

Cui, Y., Chatterjee, A., Liu, Y., Dumenyo, C. K. \& Chatterjee, A. K. (1995). Identification of a global repressor gene, RsmA, of Erwinia carotovora subsp. carotovora that controls extracellular enzymes, $\mathrm{N}$ (3-oxohexanoyl)-L-homoserine lactone, and pathogenicity in softrotting Erwinia spp. J Bacteriol 177, 5108-5115.

Cui, Y., Mukherjee, A., Dumenyo, C. K., Liu, Y. \& Chatterjee, A. K. (1999). $r s m C$ of the soft-rotting bacterium Erwinia carotovora subsp. carotovora negatively controls extracellular enzyme and harpin $\mathrm{Ecc}_{\mathrm{Ec}}$ production and virulence by modulating levels of regulatory RNA $(r s m B)$ and RNA-binding protein (RsmA). J Bacteriol 181, 60426052.

Cui, Y., Chatterjee, A. \& Chatterjee, A. K. (2001). Effects of the twocomponent system comprising GacA and GacS of Erwinia carotovora subsp. carotovora on the production of global regulatory $r s m B$ RNA, extracellular enzymes, and harpin $\mathrm{Ecc}_{\mathrm{Ec}}$. Mol Plant Microbe Interact 14, 516-526.

Cui, Y., Chatterjee, A., Hasegawa, H., Dixit, V., Leigh, N. \& Chatterjee, A. K. (2005). ExpR, a LuxR homolog of Erwinia carotovora subsp. carotovora, activates transcription of rsmA, which specifies a global regulatory RNA-binding protein. J Bacteriol 187, 47924803.

Cui, Y., Chatterjee, A., Yang, H. \& Chatterjee, A. K. (2008). Regulatory network controlling extracellular proteins in Erwinia carotovora subsp. carotovora: FlhDC, the master regulator of flagellar genes, activates $r s m B$ regulatory RNA production by affecting gacA and hexA (lrhA) expression. J Bacteriol 190, 4610-4623.

Datsenko, K. A. \& Wanner, B. L. (2000). One-step inactivation of chromosomal genes in Escherichia coli K-12 using PCR products. Proc Natl Acad Sci U S A 97, 6640-6645.

Davalos-Garcia, M., Conter, A., Toesca, I., Gutierrez, C. \& Cam, K. (2001). Regulation of osm $C$ gene expression by the two-component system rcsB-rcsC in Escherichia coli. J Bacteriol 183, 5870-5876.

de Lorenzo, V., Herrero, M., Jakubzik, U. \& Timmis, K. N. (1990). Mini-Tn5 transposon derivatives for insertion mutagenesis, promoter probing, and chromosomal insertion of cloned DNA in gramnegative eubacteria. J Bacteriol 172, 6568-6572.

Eriksson, A. R. B., Andersson, R. A., Pirhonen, M. \& Palva, E. T. (1998). Two-component regulators involved in the global control of virulence in Erwinia carotovora subsp. carotovora. Mol Plant Microbe Interact 11, 743-752.

Flego, D., Marits, R., Eriksson, A. R. B., Koiv, V., Karlsson, M. B., Heikinheimo, R. \& Palva, E. T. (2000). A two-component regulatory system, pehR-pehS, controls endopolygalacturonase production and virulence in the plant pathogen Erwinia carotovora subsp. carotovora. Mol Plant Microbe Interact 13, 447-455.

Francez-Charlot, A., Laugel, B., Van Gemert, A., Dubarry, N., Wiorowski, F., Castanie-Cornet, M. P., Gutierrez, C. \& Cam, K. (2003). RcsCDB His-Asp phosphorelay system negatively regulates 
the flhDC operon in Escherichia coli. Mol Microbiol 49, 823832.

Gervais, F. G., Phoenix, P. \& Drapeau, G. R. (1992). The $r c s B$ gene, a positive regulator of colanic acid biosynthesis in Escherichia coli, is also an activator of FtsZ expression. J Bacteriol 174, 3964-3971.

Gottesman, S., Trisler, P. \& Torres-Cabassa, A. (1985). Regulation of capsular polysaccharide synthesis in Escherichia coli K-12: characterization of three regulatory genes. J Bacteriol 162, 1111-1119.

Gupte, G., Woodward, C. \& Stout, V. (1997). Isolation and characterization of $r c s B$ mutations that affect colanic acid capsule synthesis in Escherichia coli K-12. J Bacteriol 179, 4328-4335.

Harris, S. J., Shih, Y. L., Bentley, S. D. \& Salmond, G. P. (1998). The hexA gene of Erwinia carotovora encodes a LysR homologue and regulates motility and the expression of multiple virulence determinants. Mol Microbiol 28, 705-717.

Heikinheimo, R., Flego, D., Pirhonen, M., Karlsson, M. B., Eriksson, A., Mäe, A., Kõiv, V. \& Palva, E. T. (1995). Characterization of a novel pectate lyase from Erwinia carotovora subsp. carotovora. Mol Plant Microbe Interact 8, 207-217.

Hinchliffe, S. J., Howard, S. L., Huang, Y. H., Clarke, D. J. \& Wren, B. W. (2008). The importance of the Rcs phosphorelay in the survival and pathogenesis of the enteropathogenic yersiniae. Microbiology 154, 1117-1131.

Hõrak, R., Ilves, H., Pruunsild, P., Kuljus, M. \& Kivisaar, M. (2004). The ColR-ColS two-component signal transduction system is involved in regulation of Tn4652 transposition in Pseudomonas putida under starvation conditions. Mol Microbiol 54, 795-807.

Hossain, M. M., Shibata, S., Aizawa, S. I. \& Tsuyumu, S. (2005). Motility is an important determinant for pathogenesis of Erwinia carotovora subsp. carotovora. Physiol Mol Plant Pathol 66, 134143.

Hyytiäinen, H., Sjöblom, S., Palomäki, T., Tuikkala, A. \& Palva, E. T. (2003). The PmrA-PmrB two-component system responding to acidic $\mathrm{pH}$ and iron controls virulence in the plant pathogen Erwinia carotovora ssp. carotovora. Mol Microbiol 50, 795-807.

Ilves, H., Hõrak, R., Teras, R. \& Kivisaar, M. (2004). IHF is the limiting host factor in transposition of Pseudomonas putida transposon Tn4652 in stationary phase. Mol Microbiol 51, 1773-1785.

Jones, A. M., Goodwill, A. \& Elliott, T. (2006). Limited role for the DsrA and RprA regulatory RNAs in rpoS regulation in Salmonella enterica. J Bacteriol 188, 5077-5088.

Kapatral, V., Campbell, J. W., Minnich, S. A., Thomson, N. R., Matsumura, P. \& Pruss, B. M. (2004). Gene array analysis of Yersinia enterocolitica FlhD and FlhC: regulation of enzymes affecting synthesis and degradation of carbamoylphosphate. Microbiology 150, 22892300 .

Liu, Y., Cui, Y., Mukherjee, A. \& Chatterjee, A. K. (1998). Characterization of a novel RNA regulator of Erwinia carotovora ssp. carotovora that controls production of extracellular enzymes and secondary metabolites. Mol Microbiol 29, 219-234.

Liu, Y., Jiang, G., Cui, Y., Mukherjee, A., Ma, W. L. \& Chatterjee, A. K. (1999). $k d g R_{\mathrm{Ecc}}$ negatively regulates genes for pectinases, cellulase, protease, harpin ${ }_{\mathrm{Ecc}}$, and a global RNA regulator in Erwinia carotovora subsp. carotovora. J Bacteriol 181, 2411-2421.

Livak, K. J. \& Schmittgen, T. D. (2001). Analysis of relative gene expression data using real-time quantitative PCR and the $2^{-\Delta \Delta C_{t}}$ method. Methods 25, 402-408.

Mäe, A., Heikinheimo, R. \& Palva, E. T. (1995). Structure and regulation of the Erwinia carotovora subspecies carotovora Scc3193 cellulase gene Celv1 and the role of cellulase in phytopathogenicity. Mol Gen Genet 247, 17-26.
Majdalani, N., Chen, S., Murrow, J., St John, K. \& Gottesman, S. (2001). Regulation of RpoS by a novel small RNA: the characterization of RprA. Mol Microbiol 39, 1382-1394.

Majdalani, N., Hernandez, D. \& Gottesman, S. (2002). Regulation and mode of action of the second small RNA activator of RpoS translation, RprA. Mol Microbiol 46, 813-826.

Majdalani, N., Heck, M., Stout, V. \& Gottesman, S. (2005). Role of $\mathrm{RcsF}$ in signaling to the Rcs phosphorelay pathway in Escherichia coli. J Bacteriol 187, 6770-6778.

Marits, R., Kõiv, V., Laasik, E. \& Mäe, A. (1999). Isolation of an extracellular protease gene of Erwinia carotovora subsp. carotovora strain SCC3193 by transposon mutagenesis and the role of protease in phytopathogenicity. Microbiology 145, 1959-1966.

Marits, R., Tshuikina, M., Pirhonen, M., Laasik, E. \& Mäe, A. (2002). Regulation of the expression of prtW: gusA fusions in Erwinia carotovora subsp. carotovora. Microbiology 148, 835-842.

Miller, J. (1972). Experiments in Molecular Genetics. Cold Spring Harbor, NY: Cold Spring Harbor Laboratory.

Mouslim, C., Delgado, M. \& Groisman, E. A. (2004). Activation of the RcsC/YojN/RcsB phosphorelay system attenuates Salmonella virulence. Mol Microbiol 54, 386-395.

Münch, R., Hiller, K., Grote, A., Scheer, M., Klein, J., Schobert, M. \& Jahn, D. (2005). Virtual Footprint and PRODORIC: an integrative framework for regulon prediction in prokaryotes. Bioinformatics 21, 4187-4189.

Novel, G., Didier-Fichet, M. L. \& Stoeber, F. (1974). Inducibility of beta-glucuronidase in wild-type and hexuronate-negative mutants of Escherichia coli K-12. J Bacteriol 120, 89-95.

Pavel, H., Forsman, M. \& Shingler, V. (1994). An aromatic effector specificity mutant of the transcriptional regulator DmpR overcomes the growth constraints of Pseudomonas sp. strain CF600 on parasubstituted methylphenols. J Bacteriol 176, 7550-7557.

Pérombelon, M. C. M. (2002). Potato diseases caused by soft rot Erwinias: an overview of pathogenesis. Plant Pathol 51, 1-12.

Pirhonen, M., Heino, P., Helander, I., Harju, P. \& Palva, E. T. (1988). Bacteriophage T4 resistant mutants of the plant pathogen Erwinia carotovora. Microb Pathog 4, 359-367.

Pirhonen, M., Saarilahti, H., Karlsson, M. B. \& Palva, E. T. (1991). Identification of pathogenicity determinants of Erwinia carotovora subsp. carotovora by transposon mutagenesis. Mol Plant Microbe Interact 4, 276-283.

Prüß, B. M. (2000). FlhD, a transcriptional regulator in bacteria. Recent Res Dev Microbiol 4, 31-42.

Prüß, B. M., Liu, X., Hendrickson, W. \& Matsumura, P. (2001). FlhD/ FlhC-regulated promoters analyzed by gene array and lac $Z$ gene fusions. FEMS Microbiol Lett 197, 91-97.

Prüß, B. M., Campbell, J. W., Van Dyk, T. K., Zhu, C., Kogan, Y. \& Matsumura, P. (2003). FlhD/FlhC is a regulator of anaerobic respiration and the Entner-Doudoroff pathway through induction of the methyl-accepting chemotaxis protein Aer. J Bacteriol 185, 534543.

Sambrook, J. \& Russell, D. W. (2001). Molecular Cloning: a Laboratory Manual, 3rd edn. Cold Spring Harbor, NY: Cold Spring Harbor Laboratory.

Sjöblom, S., Brader, G., Koch, G. \& Palva, T. E. (2006). Cooperation of two distinct ExpR regulators controls quorum sensing specificity and virulence in the plant pathogen Erwinia carotovora. Mol Microbiol 60, 1474-1489.

Studier, F. W. \& Moffatt, B. A. (1986). Use of bacteriophage T7 RNA polymerase to direct selective high-level expression of cloned genes. J Mol Biol 189, 113-130. 
Takle, G. W., Toth, I. K. \& Brurberg, M. B. (2007). Evaluation of reference genes for real-time RT-PCR expression studies in the plant pathogen Pectobacterium atrosepticum. BMC Plant Biol 7, 50.

Wang, Q., Zhao, Y., McClelland, M. \& Harshey, R. M. (2007). The RcsCDB signaling system and swarming motility in Salmonella enterica serovar Typhimurium: dual regulation of flagellar and SPI2 virulence genes. J Bacteriol 189, 8447-8457.
Wang, D., Korban, S. S. \& Zhao, Y. (2009). The Rcs phosphorelay system is essential for pathogenicity in Erwinia amylovora. Mol Plant Pathol 10, 277-290.

Wehland, M. \& Bernhard, F. (2000). The RcsAB box. Characterization of a new operator essential for the regulation of exopolysaccharide biosynthesis in enteric bacteria. J Biol Chem 275, 7013-7020.

Edited by: I. K. Toth 